\title{
Iranian Female Language Learners' Listening Strategy Preferences in Multimedia Environment
}

\author{
Shabnam Talebi Eskandari \\ Department of Foreign Languages, Islamic Azad University, Isfahan Branch, Isfahan, Iran \\ E-mail: shabnameskandari@gmail.com \\ Farinaz Shirani Bidabadi (Corresponding author) \\ Iranian Academic Center for Education, Culture \& Research, IUT Branch (ACECR), Isfahan, Iran \\ E-mail: Farsh5000.ukm@gmail.com
}

Received: 20-06-2016

Accepted: 04-09-2016

Published: 02-01-2017 doi:10.7575/aiac.ijalel.v.6n.1p.66

Advance Access Published: November 2016

URL: http://dx.doi.org/10.7575/aiac.ijalel.v.6n.1p.66

\begin{abstract}
Listening skill has been recently paid great attention comparing with the other three language skills since having communication is the first and most essential need. Language learners have been using the three different listening strategies (Cognitive, Meta-cognitive, and Socio-affective) to improve their listening skills in multimedia environments in particular. The main focus of this study is to determine the most preferable listening strategies employed in improving listening skills in multimedia environment by female Iranian English language learners. To achieve the goals, thirty female English language learners - twenty to twenty five - out of sixty were selected. In order to collect data IELTS test as pre-test and post-test questionnaire and interview were used. The result indicated that these language learners mainly employed meta-cognitive strategies the most in the multimedia environment. Thus, it is implied that the findings would be beneficial to the classroom practice, guide learners and lecturers as well as syllabus planners and material designers
\end{abstract}

Keywords: Multimedia environments, Listening strategy, Meta-cognitive, cognitive, Socio-affective strategy

\section{Introduction}

Among the four skills in English language, there has always been a great deal of consideration to listening, since it is a social activity in which both speakers and listeners may affect the nature of the message and how it is interpreted (Flowerdew \& Miller, 2005), thus it is considered as the most essential, complex and practical skill and is recently paid a lot of attention comparing with the other three language skills because having communication is the first and most essential need. Listening is defined as the crucial complex cognitive active process in which listeners ought to recognize the differences, discriminate between speech sounds, understand vocabulary and grammatical structures, and interpret stress and intonation (Vandergrift, 1992, 1997a, 2011; Yang, 2009, p.134; Shirani, Yamat \& Shahrokhi, 2013). In the context of the present study, communication requirements always direct learners and language learners at different proficiency level and they are not able to cope with the problems in the area of listening mastery. This problem could be observed among university learners even at the highest academic degrees, therefore they might have problems after graduation at work or in the society.

Listeners unconsciously use specified strategies while listening and that effective listening strategies contribute to better understanding and helps the learners in attaining high levels of self-confidence. Learners can develop better listening habits by the integration of listening strategies into the language learning process (Flowerdew and Miller, 2005). Ma (2015, p. 38) stated that listening strategies refer to techniques, approaches or actions that students take in their listening process to help their listening comprehension. These listening strategies are categorized under three main groups Cognitive, Metacocognive and Socio-affective -, that each has some sub categories. Cognitive listening strategies are the processes learners go through in order to acquire the language (Flowerdew \& Miller, 2005). These are thinking strategies that allow an individual to build knowledge (Ronzano, 2010). They directly work on incoming information and manipulate it in a way that increases learning (O'Malley \& Chamot, 1990, p. 44; Coskun, 2010). Meta-cognitive listening strategies are the techniques learners organize, monitor and evaluate or assess their learning with (Flowerdew \& Miller, 2005). These strategies help learners recognize whether they have accomplished a certain aspect or generalization and are methodologies that guide the learners as they attempt to monitor and control their learning process (Ronzano, 2010). Furthermore, they assist the learners in identifying the procedures and tasks which are appropriate and most expedient for solving problems and adding to their current information (Ronzano, 2010). These strategies include planning for, monitoring and evaluating the achievement of a learning activity goal (O'Malley \& Chamot, 1990, p. 44; Coskun, 2010). Socio-affective listening strategies are the strategies that can be used to enhance 
learning and encourage them to continue learning (Flowerdew \& Miller, 2005). It is also one of the ways of interacting with other people in order for the learning to be enhanced (O'Malley \& Chamot, 1990; p.44; Coskun, 2010).

With the increasing accessibility of technology and its fast pace of change, the important role of using technology is so clear for everyone that makes its ignorance almost inevitable and the people are embracing new ways to connect with others through modern day technology. The gift of developed industrial world has provided many valuable services in this regard to the point where language experts express their interest in using all possible sorts of technology, especially multimedia environments as the integration form of all of them, and emphasize its vital role in teaching. Multimedia environments must be regarded and considered as the integration of multiple forms of media. While in second language teaching and learning it most commonly involves the use of computers to present texts, graphics, videos, animations and sound tracks in an integrated way, it is formally defined as any kinds of technology that combines different sorts of media (sounds, texts, photographs or videos) into a single presentation format. Nowadays, this environment is generally associated with networked computers and their media capabilities, as graphically delivered to users via the World Wide Web (Williams, 2013). Collins (1997) defines this concept as presenting learning materials involves three or more of the following media: drawings or diagrams, animated drawings or diagrams, still photographs and other images, video clips, text (printed words), speech or other sounds. "

People with various needs of learning English in different parts of the world always have been trying new different demanding ways related to modern technology and some have been trying to approach listening skill by using various types of listening strategies so that they can consider themselves a good listener and so consequently some instruction programs have always used various methods, teaching-aid and strategies to teach listening skill in a perfect way (Chang and Lehman, 2002 and Ma, 2015). But most of them use the listening strategies without even being aware and not all of them are able to use all strategies and needless to say that they do not know how they can benefit from technology devices in a perfect way even if they use any. Hence, various research studies studied one or a variety range of just one listening strategy and they all identified their positive effects on listening skills but none of them made any attempts in multimedia environments -to emerge the effects of a mixture of two or three of the strategies along with the order of the listening strategies according to the learners' preference (Pintrich,2002 \& Shirani \& Yamat,2012) Imhof, Stain and Wolvin (1998,1999 \&2010) used metacognitive activities - Planning - in listening. Some researchers believe that selfregulation is an active, important constructive process in listening improvement which learners set learning goals and try to monitor, regulate and control their cognition and motivation (Pintrich, 2000 \& Wolvin, 2010). Pintrich (2002) organized his self-regulation model in four metacognitive strategies including: planning, self-monitoring, control and evaluation. Shirani \& Yamat (2012) discussed the strategies employed by Iranian freshmen university learners in extensive listening as attention among metacognitive strategies, visualization, and note-taking and referencing among cognitive ones and communicating and skipping among socio-affective strategies to play the leading roles. Also, Shirani and Yamat (2013) in another study research found out that four Metacognitive strategies (planning and evaluation, problem-solving, personal knowledge and directed knowledge) were employed the most while the learners were listening to English texts. Moreover, Ma (20015) tried to explore the effects of gender on listening strategy use under the internet autonomous learning environment and finds the differences and similarities in listening strategy use. Therefore, Vandergrift, Mareschal and Tafaghodtari (2006) asserted the need for validation and development of listening questionnaires, assessing listeners` metacognitive awareness, and their strategy use preferences while listening to oral tests. The five emerged metacognitive strategies are problem-solving (strategies to inference and monitor them), planning and evaluation (preparation strategies for listening and evaluation of these listening efforts), mental translation (must-avoid strategies in order to be skilled listener), personal knowledge (how difficult they find English listening and their perception of their own self-efficacy) and directed knowledge (concentration strategies) respectively. Coskun (2010) investigated the effects of only five metacognitive listening strategy training, including: planning, monitoring evaluation and problem identification on the listening performance. White (1993) examined the use of metacognitive advanced organization, selective attention, directed attention, delayed production, self-management, problem identification, self-monitoring, self-evaluation, prioritizing, revision, cognitive -repetition, resourcing, grouping, notetaking, deduction, substitution, imagery elaboration, visualization, world elaboration, between parts elaboration, contextualization, summarization, translation to and from English, Inferencing, transfer, rehearsal and socio-affective strategies - questioning, cooperation in EFL classroom situation which focused on both language learning context, including mode of the study, target language, language use opportunities and study level, and learner characteristics such as age, gender, language learning experience and other prior experiences, motivation and proficiency. Selamat \& Sidhu, (2011, together with three more researchers, O Malley \& Chamot, 1990; Oxford, 1996) examined the advantages of applying Metacognitive Strategy Instruction (MetSI) program - planning, personal knowledge, directed attention and problem-solving. As mentioned earlier, just a few trends of research studies have been focused on just some - not all of the listening strategy within multimedia environments and if there, concentrating on the effects of those environments on listening without considering listening strategies or sometimes on other different aspects of language as grammar and vocabulary. Thus, the main focus of this study is to determine the most preferable listening strategies employed in improving listening skills in multimedia environment by female Iranian English language learners.

\subsection{Research Question}

1. What are the most preferable listening strategies employed in improving listening skills in multimedia environment by female Iranian English language learners. 


\section{Literature Review}

People with various needs of learning English in different parts of the world always have been trying new different demanding ways related to modern technology and some have been trying to approach listening skill by using various types of listening strategies so that they can consider themselves a good listener and so consequently some instruction programs have always used various methods, teaching-aid and strategies to teach listening skill in a perfect way (Chang and Lehman, 2002 and Ma, 2015). But most of them use the listening strategies without even being aware and not all of them are able to use all strategies and needless to say that they do not know how they can benefit from technology devices in a perfect way even if they use any. Hence, various research studies studied one or a variety range of just one listening strategy and they all identified their positive effects on listening skills but none of them made any attempts in multimedia environments -to emerge the effects of a mixture of two or three of the strategies along with the order of the listening strategies according to the learners' preference (Pintrich,2002 \& Shirani \& Yamat,2012) Imhof, Stain and Wolvin $(1998,1999$ \&2010) used metacognitive activities - Planning - in listening. Some researchers believe that selfregulation is an active, important constructive process in listening improvement which learners set learning goals and try to monitor, regulate and control their cognition and motivation (Pintrich, 2000 \& Wolvin, 2010). Pintrich (2002) organized his self-regulation model in four metacognitive strategies including: planning, self-monitoring, control and evaluation. Shirani \& Yamat (2012) discussed the strategies employed by Iranian freshmen university learners in extensive listening as attention among metacognitive strategies, visualization, and note-taking and referencing among cognitive ones and communicating and skipping among socio-affective strategies to play the leading roles. Also, Shirani and Yamat (2013) in another study research found out that four Metacognitive strategies (planning and evaluation, problem-solving, personal knowledge and directed knowledge) were employed the most while the learners were listening to English texts. Moreover, Ma (20015) tried to explore the effects of gender on listening strategy use under the internet autonomous learning environment and finds the differences and similarities in listening strategy use. Therefore, Vandergrift, Mareschal and Tafaghodtari (2006) asserted the need for validation and development of listening questionnaires, assessing listeners` metacognitive awareness, and their strategy use preferences while listening to oral tests. The five emerged metacognitive strategies are problem-solving (strategies to inference and monitor them), planning and evaluation (preparation strategies for listening and evaluation of these listening efforts), mental translation (must-avoid strategies in order to be skilled listener), personal knowledge (how difficult they find English listening and their perception of their own self-efficacy) and directed knowledge (concentration strategies) respectively. Coskun (2010) investigated the effects of only five metacognitive listening strategy training, including: planning, monitoring evaluation and problem identification on the listening performance. White (1993) examined the use of metacognitive advanced organization, selective attention, directed attention, delayed production, self-management, problem identification, self-monitoring, self-evaluation, prioritizing, revision, cognitive -repetition, resourcing, grouping, notetaking, deduction, substitution, imagery elaboration, visualization, world elaboration, between parts elaboration, contextualization, summarization, translation to and from English, Inferencing, transfer, rehearsal and socio-affective strategies - questioning, cooperation in EFL classroom situation which focused on both language learning context, including mode of the study, target language, language use opportunities and study level, and learner characteristics such as age, gender, language learning experience and other prior experiences, motivation and proficiency. Selamat \& Sidhu, (2011, together with three more researchers, O Malley \& Chamot, 1990; Oxford, 1996) examined the advantages of applying Metacognitive Strategy Instruction (MetSI) program - planning, personal knowledge, directed attention and problem-solving.

\section{Methodology}

\subsection{Design of the study}

In this quantitative experimental research, the researchers followed some specific patterns included advancing the theory, collecting data and testing it in order for confirming or disconfirming the theory based on the results. To measure and observe attitudes or behaviors of participants, some instruments were used and then the scores were collected to confirm or refute the hypothesis of the study. In other words, the underlying theory in this quantitative research provided an explanation or prediction about the relationship between variables.

\subsection{Participants}

In order to choose the participants, thirty out of sixty students (native speakers of Persian) studying EFL at Parastoo Institute aged 20 to 25 , were randomly chosen. To avoid any doubt about the language proficiency level of the participants, Cambridge Practice Test for IELTS 1 (Jakeman \& Mcdoerll, 1998) was used. The learners' language proficiency revealed that all selected participants were at the intermediate level. They were, then again, randomly divided into two groups -Control group (fifteen) and Experimental group (fifteen).

\subsection{Instruments}

Generally, several instruments were used in this quantitative experimental research. First, the standard perfect Cambridge Practice Test for IELTS 1 (Jakeman \& Mcdoerll, 1998) was used as a pre-test to determine the participants' language proficiency level. This standardized test was chosen because it is a standard test, a perfect way of determining the proficiency level and contains 40 multiple questions. The second instrument used in this study was a Listening Strategy Questionnaire included twenty eight questions, and just a few questions were adopted from (Vandergrift and Goh ,Mareschal and Tafaghodtari (2006); Vandergrift \& Goh, 2012). The questionnaire was also translated to Persian. It was arranged based on five scales referring to different degrees of agreement and disagreement, and all of the questions were mainly focused on three major listening strategies (meta-cognitive, cognitive and socio-affective), along with their sub-categories and sub-divisions. The third instrument was specified software for this study which was programmed based on Top Notch books, Fundamental level, included just two units - unit eight and nine- (Saslow \& 
Ascher, 2006). This software covered different parts of the book such as vocabulary, grammar explanations, grammar exercises, conversations and listening comprehensions. Almost all sections of the unit were decided to be included in the software based on the research questions. For better result, a Power Point File was also used just after the training. The software also covered the three above-mentioned listening strategies as well as planning, monitoring and evaluation (sub-categories of metacognitive strategies), inferencing, elaboration, summarization, translation, transfer, repetition, resourcing, grouping, note taking, deduction/induction and substitution (sub-categories of cognitive strategies), and questioning for clarification, cooperation, lowering anxiety, self-encouragement and taking emotional temperature (subcategories of socio-affective strategies). As sub-divisions, advanced organization, directed attention, selective attention and motivational management for planning; auditory monitoring and double-check monitoring for monitoring; performance evaluation and problem identification for evaluation; linguistic inference, voice inferencing, paralinguistic or kinetic inferencing and extra-linguistic inferencing; personal elaboration, word elaboration, academic elaboration, questioning elaboration, creative elaboration and imagery for elaboration.

Since the current study employed a questionnaire, there was a need to pilot the instrument to determine the reliability of the questionnaire. According to Babbie (2007), reliability refers to the fact that if a given technique is applied repeatedly to the same object, it will yield the very finding at each time. Therefore, to assess the reliability of the questionnaire in this study the most commonly used value test, Cronbach's Alpha, was applied. The questionnaire was adapted and modified, though. Thus, the pilot study was conducted on a group of 10 Iranian learners at Parastoo Institute. Of course, these learners did not participate in the real research study. The findings of the pilot study of Listening Strategy Questionnaires, that is the Cronbach's reliability coefficient for 28 items, indicated that the scale was reliable with the Cronbach's Alpha value of 0.813 .

\subsection{Data analysis}

The aim of the current study was to determine the learners' English listening proficiency levels, to identify the listening strategies they employed in multimedia environment. Therefore, the data associated to the learners' listening strategy use was collected through the Listening Strategy Questionnaire both in pre-test and post-test stages to determine the learners' English listening proficiency levels and listening strategies employed in multimedia environment. Then, descriptive statistics (means, standard deviations and frequencies/percentages) were utilized to rank the strategy categories from the most frequent to the least frequent. In other words, finding out whether the learners employed metacognitive, cognitive, or socio-affective strategies in the process of listening.

\section{Findings and Discussions}

\subsection{Iranian Female Language Learners' Listening Strategies Preferences in Multimedia Environment}

The following Table 1 shows the learners' preferences toward the three main listening strategies that single strategy or the mixture of strategies are used more often by female language learners. The reports to this question have been provided in the form of comparative descriptive statistics (mean and standard deviation ) for the three strategies as well as for the pre-test and the post-test results in the experimental and control groups. The learners are divided into two groups - control and experimental - 15 people per group taking both pretest and post-test on the basis of the three strategies including metacognitive, cognitive and socio affective. The minimum score of the pre-test in experimental group was 4 and the maximum score was 35. There is also a big difference between the mean of pre-test, 11.06 and the mean of post-test, 21.04 in the experimental group. On the other hand, minimum score of both pre-test and post-test in control group was the same (9.0), and considering the maximum score, the post-test score is even less than pre-test in the same group and consequently There is not any big difference between the mean of pre-test, 11.44 and the mean of post-test, 11.66 in the control group It could be stated that metacognitive strategy is the learners' most frequent strategy.

Table 1. Descriptive Statistics

\begin{tabular}{lllllll}
\hline & & N & Minimum & Maximum & Mean & Std. Deviation \\
\hline \multirow{2}{*}{ Strategy } & Metacognitive & 60 & 3.00 & 4.67 & 3.8984 & .39087 \\
& Cognitive & 60 & 2.93 & 4.73 & 3.7476 & .41947 \\
& Socio-affective & 60 & 2.25 & 5.00 & 3.8792 & .60101 \\
\hline \multirow{2}{*}{ Experimental } & Pre-test & 15 & 4.00 & 19.00 & 11.0667 & 4.36654 \\
& Post-test & 15 & 11.00 & 35.00 & 21.4000 & 8.25314 \\
Control & Pre-test & 15 & 9.00 & 15.00 & 11.4667 & 1.68466 \\
& Post-test & 15 & 9.00 & 14.00 & 11.6667 & 1.49603 \\
\hline
\end{tabular}

The questionnaire was given to 60 EFL learners. The largest difference between minimum score of 2.25 , and the maximum score of 5, is associated with the socio-affective strategy. The mean for Metacognitive Strategy is 3.89 , which is the highest, while the lowest mean of 3.74 belongs to the Cognitive strategy, and the mean for Socio-affective Strategy is 3.87 which is in the mid-level. There were 15 learners in control and experimental group each. The 
minimum score of the pre-test in experimental group was 4 and the maximum score was 35 . There is also a big difference between the mean of pre-test, 11.06 and the mean of post-test, 21.04 in the experimental group. In other words, it can be concluded that there is a significant difference between the three strategies in students' opinions and students have positive attitudes toward metacognitive and socio-affective strategies, while there is no significant difference between these two strategies. But Table 2 reveals the comparison of the cognitive strategy with the other two, a significant difference was reported and cognitive strategy had the lower rate than metacognitive and socio-affective strategies

Table 2. The capitals, assets and revenue in listed banks

\begin{tabular}{lllc}
\hline & Total capital stock & Income of main business & Total assets \\
\hline Pudong Development Bank & 39.2 & 214.7 & 5730.7 \\
\hline Bank of China & 459.4 & 3345.7 & 59876.9 \\
\hline
\end{tabular}

As displayed in Table 3, the Mean Rank of the Metacognitive, Cognitive and Socio-affective strategies are 95.54, 76.13 and 99.83 respectively. The Chi-Square is 7.069 or 2 with the significant level of 0.029 , which is less than 0.05 . So the learners' attitudes toward the strategies are significantly different, so stated earlier cognitive strategy had the lower rate comparing with the other strategies.

Table 3. Descriptive Statistics Ranks \& Test Statistics

\begin{tabular}{llc}
\hline & N & Mean Rank \\
\hline Metacognitive & 60 & 95.54 \\
Cognitive & 60 & 76.13 \\
Socio-affective & 60 & 99.83 \\
Total & 180 & \\
\hline Chi-Square & 7.069 & \\
Df & 2 & \\
Asymp. Sig. & .029 & \\
\hline
\end{tabular}

To manifest the exact difference between the strategies and find out the strategy which is completely different from the other one, the Mann-Whitney Test (two by two strategy comparisons) was utilized. The following table indicates that the metacognitive strategy was mostly preferred by the participants. The mean rank of the language learners is calculated 66.09 for Metacognitive, and 54.09 for Cognitive strategy. The Mann-Whitney U Test is 1415.5, and Z = 2.021 with the significant level of 0.043 which is less than $\alpha(\operatorname{sig}<0.05)$. This number indicates a significant difference between these two strategies. The mean rank of the Metacognitive strategy is more than the one for Cognitive strategy. The mean rank of Metacognitive and Socio-affective strategies are measured 59.13 and 61.87 in a respective order. The Mann-Whitney U Test is 1718.000 , and $Z=-0.432$ with the significant level of 0.666 which is more than $\alpha$ (sig. 0.05 ). Hence, there is no significant difference between Metacognitive strategy and Socio-affective. The obtained mean rank of the Cognitive strategy is 52.54, while the one for Socio-affective strategy is 68.46. The Mann-Whitney U Test is 1322.5 , and $Z=-2.514$ with the significant level of 0.012 which is less than $\alpha$ (sig. 0.05). It confirms a significant and sharp difference between these two strategies. The mean rank of the Socio-affective strategy is more than the mean rank for the Cognitive strategy.

Table 4. Descriptive Statistics Ranks \& Test Statistics

\begin{tabular}{lllll}
\hline & $\mathrm{N}$ & Mean Rank & Mean Rank & Mean Rank \\
\hline Metacognitive & 60 & 66.91 & 59.13 & - \\
Cognitive & 60 & 54.09 & - & 52.54 \\
Socio-affective & 60 & - & 61.87 & 68.46 \\
Total & 180 & & & \\
\hline Mann-Whitney U & & 1415.500 & 1718.000 & 1322.500 \\
Z & & -2.021 & -.432 & -2.514 \\
Asymp. Sig. & & .043 & .666 & .012 \\
\hline
\end{tabular}

Hence, the metacognitive strategy was mostly preferred by the participants (Table 1), the cognitive strategy had the 
low-frequency usage, and the socio-affective strategy was placed on the mid-level. In other words, it is concluded that metacognitive strategy was mostly preferred by the learners, they preferably would rather use metacognitive, socioaffective and cognitive strategies in a respective order. As Shirani, Yamat \& Shahrokhi (2013) explored the similarities and differences between the preference of different strategies and the ways these strategies were employed by Iranian female freshmen, using the findings of the interviews and think-aloud protocols in narrow listening. All three listening strategies -five metacognitive, five cognitive and two socio-affective- were included in their research and the results revealed that the students prefer to use metacognitive and then cognitive strategy rather than socio-affective listening strategies in narrow listening. It also reported that strategies could facilitate listening comprehension because of the students 'involvement in preparation and planning. In fact, they are thinking about what they need and how they intend to achieve it.

\section{Conclusion}

The findings of this study illustrated that multimedia environment, movies, or any other technology devices play an important role in improving listening skill through teaching listening strategies and great efforts were made to explore any single or mixtures of the listening strategies that is/are mostly used by Iranian language learners in the multimedia environments. Both groups had the same findings in pre-test but there was a significant difference between the mean score of pre-test and post-test in each group, as well as between the post-test scores in control and experimental group. The findings proved that there is a significant difference between the three strategies in learners' opinions and learners have positive attitudes toward metacognitive and the socio-affective strategies, while there is no significant difference between these two strategies. But comparing the cognitive strategy with the other two, a significant difference was reported and cognitive strategy had the lower rate than metacognitive and the socio-affective strategies. Hence, the metacognitive strategy was mostly preferred by the participants, the cognitive strategy had the low-frequency usage, and the socio-affective strategy was placed on the mid-level. On the other hand, the mean of pre-test and post-test scores in the control group had no significant difference, but the mean of pre-test and post-test scores in the experimental group were significantly different. The scores of the post-test of the experimental group were significantly higher than those of the control group which showed the listening strategy instruction in multimedia environment increases the quality of listening performance. The findings of the questionnaire proved that the scores of the post-test of the experimental group were significantly higher than those of the control group which demonstrated the fact that the listening strategy instruction in multimedia environment expands the listening performance.

\subsection{Implication of the Study}

The findings of this study have practical implications in three aspects: for learners to be good listeners, for instructors who intend to have better class teaching performance, and for curriculum designers who plan to write strategy-based textbooks. The findings of this study have some pedagogical implications as well. Textbooks and materials are considered to be the essential parts in any teaching programs, so much that they can affect the whole instruction program, mainly including students' and teachers' achievements. Curriculum and material designers and textbook writers can find the results of this study helpful. Listening tasks and exercises must be designed in a way that the listeners can use different listening strategies, be able to have better achievements in the process of listening development and be a professional listener. Besides, the designers should design a curriculum in a way to motivate learners and promote their listening proficiency. Listening texts should be challenging, in which, strategies can effectively be embedded. The textbooks are also required to be written in order to involve a variety of listening materials so that they can be helpful for different leaners and be in relation with their listening proficiency test. Of course their negative effects need to be concerned. Regarding the proved role of technology and multimedia devices, the curriculum designers and textbook writers should take advantage of them and use them in writing and designing the textbooks and curricula. Thus, the designers should write textbooks based on strategy instruction along with appropriate technology device as the findings of this study proved.

Another aspect of implication of this research study's findings is related to the methodology. Hence, it will be of interest for teachers and instructors. The critical educational goal in every listening course is developing listening skill and improving listening ability through teaching listening strategies as well as helping students to be successful listeners. Instructors can get benefit of the findings of this study to teach the listening strategies in the most perfect way. Just like the curriculum designers, teachers should also use the findings of this study to motivate their students through teaching the strategies. Considering the results, teachers can start teaching the strategies based on the order of learners' preferences, that is metacognitive, socio-affective and cognitive strategies. They should use a multi-aspect teaching method that motivates the learners to use metacognitive and socio-affective strategies and develop cognitive strategies. The results could also be beneficial to the class practice. Meanwhile, the teachers should be able to develop their own strategy training models, even for their local contexts, reflecting upon their different experiences. Language learners would also agree that this study might be helping them by making them be aware of their strategy preferences and identify their own strategy on problematic areas so that their performance could be developed. According to Riazi and Riasati (2007); Shirani and Yamat (2012) being aware of different strategies and strategy preferences can improve learners' self-confidence and self-esteem. Generally speaking, when the learners feel comfortable and aware of their condition, they can have the experience of better and more successful learning 


\section{References}

Chang, M.M, \& Lehman, J.D. (2002). Learning foreign language through an Interactive multimedia program: An experimental study on the effects of the relevance component of the ARCS model. Calico Journal, 20(1), P-P 81-98.

Collins, J., Hammond, M., \& Wellington, J. (1997). Teaching and learning with multimedia. London and New York: Routledge.

Coskun, A. (2010). The effects of metacognitive strategy training on the listening performance of beginner students, Novitas Royal, 35-50.

Flowerdew, J., \& Miller, L. (2005). Second language listening: theory and practice. Cambridge: Cambridge University Press.

Imhof, M. (1998). What makes a good listener? Listening behavior in instructional settings. International Journal of Listening, 12, 81-105

Jakeman, V, \& McDawel, C. (1996). Cambridge IELTS 1. United Kingdom: Cambridge University Press.

Ma, X. (2015). Listening strategies use in the internet learning environment by non-English major college students: A comparison between male and female listeners, .International Journal of Culture and History, 2(2332-5518).

O'Malley, M.J., Chamot, A. U. (1990). Learning Strategies in second language acquisition. England: Cambridge University Press

Oxford, R. L. (Ed.). (1996). Language learning strategies around the world: Cross-cultural perspectives. Manoa, HI: University of Hawaii Press.

Pintrich, P. R. (2000). The role of good orientation in self-regulated learning. Handbook of self-regulation ( pp. 451=502). San Diego, CA: Academic Press.

Riazi, A., \& Riasati, M. J. (2007). Learning language style preferences: A case study of Shiraz EFL Institutes. The Asian EFL Journal Quarterly, 9(1), 97-125.

Ronzano, S.J. (2010). Effectiveness of Metacognitive strategies for improving reading comprehension in secondary students. The United States of America: Dissertation Publication.

Saslow,J., \& Ascher, A. (2006). Top Notch, Fundamentals. The United States of America: Pearson Education.

Selamat.S. , \& Sidhu. G.K. (2011). Students perception of Metacognitive strategy use in lecture listening comprehension. Language education in Asia, 2(2), 185-195.

Shirani. F., \& Yamat. H. (2012). The relationship between English listening proficiency Levels and learning styles. Journal of language studies, 12(4), 1041-1055.

Shirani.F., \& Yamat .H. (2013). EFL learners' perceptions toward Meta-cognitive strategy use in English language listening .Journal of language studies, 13(3), 31-43.

Stein, S.K. (1999). Uncovering listening strategies: Protocol analysis as a means to investigate student listening in the basic communication course, Unpublished PhD dissertation, University of Maryland, College Park, MD.

Tajzadeh. P., Khodabandehlou. M., Jahandar. S,. \& Najafi. M. (2013). The Impact of Socio affective strategies on Iranian Intermediate EFL learner's speaking ability. Indian Journal of fundamental and applied life sciences, 3(3), 670674.

Vandergrift, L. (1992). The comprehension strategies of second language (French) listeners. PhD Thesis, University of Alberta, Canada.

Vandergrift, L. (1997). The comprehension strategies of second language (French) listeners: A descriptive study. Foreign Language Annals, 30, 387-409.

Vandergrift, L., Goh.C., Mareschal.C.J., \& Tafaghodtari.M. (2006).The Metacognitive awareness listening questionnaire (MALQ): Development and Validation. Language learning research club, 431-462

Vandergrift, L. (2007). Recent development in second and foreign language listening comprehension research, Language Teaching, 40, 191-210.

Vandergrift, L. (2011). second language listening: presagr, process, product and pedagogy. In Eli Hinkel (Ed). Handbook of research in second language teaching and learning, volume II. (pp. 455-471). New York: Routledge, Taylor \& Francis.

Vandergrift, L .\& Goh.C. (2012). Teaching and Learning Second Language Listening: Metacognition in action. New York and London: Routledge, Taylor \& Francis.

White.C.J. (1993). Metacognitive ,Cognitive ,Social and affective strategy use in foreign language learning: A Comparative Study . PhD Thesis, Massey University.

Williams. Z .C. (2013).The use of Multimedia materials in teaching Chinese as a Second language and pedagogical implication. Masters Theses. Paper 1016, 1-74

Wolvin, A. (2010). Listening and Human Communication in in the $21^{\text {st }}$ Century. United Kingdom: Blackwell Publication.

Yang, C. (2009). A study of meta-cognitive strategies employed by English Listeners in an EFL setting. International Education Studies, 2(4), 134-139. 